\title{
The Information Society and its Consequences: Lessons from the Past
}

\author{
Jan HOLVAST \\ Holvast \& Partner, Privacy Consultants, NL - Landsmeer. henp.holvast@wxs.nl \\ Penny DUQUENOY \\ Middlesex University,London.p.duquenoy@mdx.ac.uk \\ and Diane WHITEHOUSE \\ European Commission, Brussels. diane.whitehouse@cec.eu.int
}

Key words: Consequences of ITC, control, debate, evolution, impact, information society, inventory, lessons, revolution, teaching impact of IT

\section{INTRODUCTION}

Without doubt the year 1976 was an important year for the discussion on Computers and Society. In that year Joseph Weizenbaum's Computer Power and Human Reason was published and IFIP's TC 9 on Computers and Society was founded. In this contribution we want to give a short overview of the history since then and answer the question "what lessons can be learned from the past twenty-five years?" Following a review of the vigorous debate on the development of computers in society that has taken place during that period, four main questions are raised:

1. Is the Information Society a new phenomenon or is it a question of emphasis?

2. Has the development led to a new revolution as never seen before, as many scientists and policy makers would have us believe?

3. What are, in a general sense, the consequences of this evolving information society?

4. Can information technology be controlled, and if so, what are the main instruments of control? 


\section{COMPUTERS AND SOCIETY}

The history of the Computer and the history of Computers and Society do not run in parallel. Despite the work and the ideas of forerunners, like Schickard, Pascal, von Liebnitz, Babbage, Hollerith and many others, the history of the computer can be seen as having started in the mid 1930s, when Turing, Zuse and Aiken were producing working computers with a practical function. The real start however was shortly after the end of the Second World War.

The consequences of computers on society were first seen in the field of labour. This is not surprising when we look at the enormous amount of literature devoted to the relationship between technology in general and work. Commencing with the influence of industrialisation and work in the middle of the 19th century through to the publications in the 1960s, we see a history of incremental development. It is one continuing story, in which sociologists and political scientists play a dominant role. Predictions that computer technology would soon create revolutionary changes in the number of people employed and in the length of the working week date from the late 1950 s and early 1960 s. At the same time we see the effects upon the content of the work studied and discussed.

Surprisingly in the middle of the 1960 s, there was one other field where the consequences of computing were seen very sharply: privacy. In 1967 the famous and influential book Privacy and Freedom by Alan Westin was published [24]. This book was the finishing touch to a project on "The Impact of Science and Technology on Privacy' that was carried out between 1962 and 1966. Alan Westin was Director of Research of the project. Following this publication there were a number of articles and books on this subject. There was a change of emphasis from the computer as the cause of threats to privacy, to its role in data processing. An important difference with those publications dealing with labour questions is that it was not sociologists or political scientists writing about the issue this time, but lawyers. There are several other fields where the implications of computing were perceived and studied [21]. The organisational consequences are quite substantial, and one major issue has always been the extent to which the introduction of the computer leads to greater organisational centralisation. At the same time it became clear that the computer would, in any case, affect society at large: the growth in the service sector. Already by the 1950 s over half of the United States labour force was employed in service industries, although it was argued that the shift would continue to progress gradually.

It was theorised that radical changes could be expected if computerised information systems were to be used as efficiently and effectively in the political decision-making process. Such amenities as education and medical 
care could be provided to all members of society. The relationship between computers and democracy received greater attention. Some believed that more and more decisions would be placed in the hands of experts, whereas others believed that computers could be used to establish a system of direct democracy. Ideally citizens should have a direct voice in political decisionmaking. Through the sheer amount of information and the number and speed of new discoveries, there could be great difficulty for people in trying to keep 'well informed'.

Therefore computers could have a great effect on education. In other words, the computer was seen as an aid in the process of using knowledge. Using computers in schools for instructional purposes was an important challenge, although computers raised the fear that they would increase dehumanisation by substituting machines for live teachers.

Computers were seen as having major consequences for the natural as well as the social sciences when computers were used for both data analysis and problem solving. One field, art, was seen as rather futuristic: "The use of computers in the arts has often been a subject of either good-natured humour or ridicule." [21, p.19] Somewhat greater progress has made towards an understanding of human cognitive processes. Cybernetic research compares the functioning of the human brain with the functioning of computers.

Many of the developments and implications outlined above are from the reader on computers and society, The Computer Impact, the first attempt to bring essays on implications of computer technology together in one volume. As the editor, Irene Taviss, stated, the essays are intended to present a broad sampling of the major issues raised. They were selected to give the reader a sense of the concrete developments of computer technology and their implications in specific spheres of social activity. Taviss hesitated on the choice of the title, although the most appropriate title for a discussion on the social implications of computer technology might appear to be Computers: Curse or Blessing? It is clear that the computer generated great fears and great hopes. "It has become a symbol for all that is good and all that is evil in modern society." [21, p.3]

Although this book was one of the first with a general overview and a vision of computers in society as a whole, it was important not necessarily for the attention it received, but for the discussion that was generated as a result.

The real start of the social discussion on Computers and Society was probably the publication of Daniel Bell's The Post-Industrial Society [2]. Bell's analysis posits that the advanced countries were moving from the industrial stage towards a 'post-industrial stage' of development. $\mathrm{He}$ claimed that the majority of economically active people would earn their living from different kinds of post-industrial service sector occupations. In a 
pre-publication 'he indicated his notion of a 'knowledge society', characterised by research and development and a knowledge field with a large proportion of the Gross National Product and a large share of employment [1]. Although his analysis was North American in orientation, we can assume it could be extended to a variety of other countries.

As Annti Kasvio [17] rightly observes, the term 'post-industrial' was however used for the first time by Alain Touraine in his book La societé post-industrielle, which was published in 1969. In this book, and following the tradition of sociologists dealing with computer technology, Touraine studied the consequences of the new society on labour and the industrial working class.

\section{A BREAKTHROUGH IN THE DISCUSSIONS - THE WEIZENBAUM PERIOD}

In 1976 a book was published that influenced the discussion on computer and society in an enormous way. It was Joseph Weizenbaum's Computer Power and Human Reason [22]. In this book the way in which computers can be used is criticised for the first time, specific applications are censored or perhaps even 'excommunicated'. Weizenbaum had been shocked by the way people reacted towards the computer program ELIZA, that he had designed to play the role of a psychologist or doctor. This experience led him to attach new importance to the question of the relationship between the individual and the computer.

In his analysis Weizenbaum came to the conclusion that too much power is given to technology, in particular the computer. Many problems are seen as technical problems that can be solved by a computer. The computer is seen as more powerful than human beings, and 'common sense' is replaced by science. The consequence is an over-emphasis on rationality and instrumentalism. Those who protest against this development are perceived as anti-technological, anti-scientific and, finally, as antiintellectual. In reality, however, the price - which in Weizenbaum's view is actually paid - is servitude and impotence. Therefore human beings, in particular scientists and engineers, have responsibilities that transcend their situation. Every individual must act as if the whole future of the world, of humanity itself, depends on him or her.

Two kinds of computer applications might either not be undertaken at all, or - if they are contemplated - should be approached with the utmost caution. The first kind includes all projects that propose to substitute a computer system for a human function that involves interpersonal respect, understanding, or love. These are the human functions for which computers ought not to be substituted. The second kind of computer application that 
ought to be avoided is that which can easily be seen to have irreversible and not entirely foreseeable side effects. If computers cannot be shown to meet a pressing human need that cannot readily be met in any other way, then their use ought not to be pursued.

\section{THE BEGINNING OF THE DEBATE ON THE IMPACT OF THE INFORMATION SOCIETY}

The growth of interest in computers and information technology is largely due to this initial publication by Weizenbaum. Other resulting publications are two voluminous books published in 1979 and 1980. The first is The Computer Age: A Twenty-Year View, edited by Michael Dertouzos and Joel Moses [8], the second The Microelectronic Revolution, edited by Tom Forester [11]. Both books have similar content, although not necessarily treated in the same order. Dertouzos and Moses' publication contains five main chapters: Prospects for the Individual, Trends in Traditional Computer Uses, Socio-economic Effects and Expectations, Trends in the Underlying Technologies, and Critiques. Forester's book starts, as promised in the title, with the technical: The Micro-electronic Revolution, followed by Economic and Social Implications, and ends with a view of the future: The MicroElectronic Age. Although many of the impacts of computing are mentioned, in both books the emphasis is on economic aspects, in particular, the impact for employment and labour.

It is both remarkable, and at the same time revealing, that in both volumes three articles are copied. The first is Bell's famous article on information society, ${ }^{1}$ the second a critical reaction of Weizenbaum on Bell's ideas, and the third a reply to Weizenbaum by Bell. Since these articles are widely discussed and have each in their own way contributed to a more general discussion of the social implication of information society, we will give a short overview of them.

In the comprehensive tradition of his earlier publications Bell gives an overview of the changes on societal level [4, pp. 163-212]. What he was calling in 1968 the Knowledge Society and in 1973 the Post Industrial Society, becomes the Information Society, a term that has since been adopted to describe this society. In Bell's view, we are living in a society in which information and knowledge are the crucial variables. This information explosion can only be handled through the expansion of computerised and subsequently automated information systems. This means that the computer is only a tool for managing mass society, since it is the mechanism that orders and processes the transactions - whose huge number has been mounting almost exponentially because of the increase in social interactions. His basic premise is "that knowledge and information" are 
becoming the strategic resource and transforming agent of the postindustrial society. Inevitably, the onset of far-reaching social changes, especially when they proceed as these do through the medium of specific technologies, confronts a society with "major policy questions". In his view, any technology, such as the computer, is only instrumental, and its impact depends on other social and cultural factors.

In his response Weizenbaum speaks of the 'Computer' Revolution - to make clear that it is not information that causes the changes but the computer [439-463]. He agrees that society is transforming into an information society, however it is not information that is responsible for that but the computer. The central question therefore is not who is responsible for the information, but who is responsible for the actions based on these computer systems. The crucial issue is that of responsibility and control, and the consequences of the computer.

In his reply Bell does not add anything to the content of the argument. He begins with the remark that Weizenbaum is knocking down an open door. He repeats that the computer is purely instrumental. The crucial decisions are sociological, not technological. In his view Weizenbaum is a moral absolutist with tunnel vision.

Clearly stark positions are taken up. While both authors agree that we are tending to live in an information society, their analysis differs and, with that, so do their questions as to what has to be done to prevent unforeseen, and unwanted, side effects. In Bell's vision it is information and knowledge that determine the development and there is nothing that can or should be done to handle or correct this development. Weizenbaum on the other hand blames the computer and incites human beings, especially scientists, to take up their responsibility and raise questions such as: "Who is the beneficiary of our much-advertised technological progress and who are the victims? What limits ought we, the people in general, and scientists and engineers particularly, to impose on the applications of computation to human affairs? What is the impact of the computer, not only on the economies of the world or on the war potential of nations and so on, but on the self-image of human beings and on human dignity? What irreversible forces is our worship of high technology, symbolized most starkly by the computer, bringing into play? Will our children be able to live with the world we are here and now constructing? Much depends on answers to these questions" [23].

In a sense the Weizenbaum-Bell dispute is the forerunner of the debate which still dominates today. It is not only information versus computer, but it is also the discussion between the optimist and the pessimist, between people who see information technology as a societal blessing and those who only see the darker side, the side of the shadow. The discussion between information and technology was more or less decided in favour of the latter, when Tom Forester presented his next volume on The Information 
Technology Revolution [12]. From that time on everybody talked of the new science of collecting, storing, processing, and transmitting information. Although the position seems to be a compromise between Weizenbaum and Bell, in reality the emphasis is always on technology.

\section{SOCIAL IMPLICATIONS AND THE TEACHING CURRICULUM}

Already in the beginning of the 1970s there began a search for a curriculum on Computers and Society. Among the first to raise attention to this idea was E. Horowitz and his colleagues, who cited three purposes for such a course:

- To educate computer scientists on the present and future impact of computer technology;

- To investigate some of the difficult moral questions concerning the responsibility of scientists; and,

- To gain a more humanistic perspective on the use and misuse of computers. [14]

Some years later these courses were elaborated in more detail. Two of them became more or less examples of university-level courses, because they had a broader impact and were more seriously discussed in the literature. Willy Jensen made a distinction between the broad arena where the consequences of computers were to be observed [16]:

- Economic life: trade, industry, automation, management, structural changes;

- Government: new services, bureaucracy;

- Work: employment, quality of labour;

- Culture: education, communication, informational media, quality of information, minorities;

- Leisure: quality of life, social contacts, entertainment, telework.

All of these developments were seen to have important consequences on democracy, freedom, protection of privacy, welfare and possibilities of control

A most important and useful classification was made by Friedrich, who classified the consequences of computing into the social aggregate hierarchy of international, national, business and individual levels [15]:

International level: the battle on the information market. Examples are the exploitation of databases, communication satellites, and the computer industry.

National level: national information monopolies, technology policies. Political questions are solved with computer supported planning and 
decision systems, networking, the gap between citizen and government, vulnerability of society due to the dependency on information.

Business level: quality of work, employment, control of the workplace, personal information systems.

Individual level: man in control. Loss of individual space of freedom, privacy, technical relations instead of human relations, technical help instead of human help.

\section{THE POST WEIZENBAUM PERIOD}

After publication of the volumes by Dertouzos and Moses, and Forester, a whole range of books were published detailing the social implications of the information society - very often as a spin-off of a conference devoted to such a theme or as a specific project such as in IFIP-WG9.2 [5]. This period culminated in The Information Age trilogy of Manuel Castells in which he searches for the social and economic dynamics of the information age [7]. In these books Castells sees as his main task the analysis of the informational modes of development of societies. This analysis revolves around three fundamental axes: the changes that take place in the areas of material production, human experiences, and the structures of power. Two main trends are seen as the driving force: globalisation of the economy and the digital revolution.

In the mid 1990s, when information was recognised as an important factor of economic growth, we see a political interest emerging. One of the early actors in this field was the Japanese Ministry of Industry and Trade (MITI), which made Japan the global leader in the development and production of microelectronics [17]. After the stock market crash in 1987 and the economic recession in the early 1990s many political leaders looked to the digital revolution as a form of salvation. We can cite, as an example, the United States' National Information Infrastructure Programme, launched by president Bill Clinton and vice-president Al Gore.

This kind of stance was taken up in the European Commission's report 'Europe and the Global Information Society'. The report was prepared for the European Council meeting in Corfu by the so-called High-Level Group on the Information Society, chaired by Martin Bangemann [13]. The report starts with two key messages. The first is that the advent of the information society is inevitable and will lead to an industrial revolution comparable to that of the 19th century. The second is that Europe's entry into the information society will be, as stressed also by Jacques Berleur and JeanMarc Galand in this book, market-driven. Therefore a common regulatory framework must be set up at the level of the European Union in order to 
maximise the effect of the market while guaranteeing an appropriate level of protection for intellectual property, personal data, and network security.

This last statement is noteworthy insofar as, for the first time at international level, it was accepted and admitted that the development towards an information society is accompanied by risks. "The main risk lies in the creation of a two-tier society of have and have-nots, in which only a part of the population has access to the new technology, is comfortable using it and can fully enjoy its benefits." $[13,8]$ but this is not the only risk. A regulatory response is also needed in key areas like intellectual property, privacy and media ownership. Above all encryption becomes increasingly important, with the provision that governments need power to override encryption for the purpose of fighting against crime and protecting national security.

Whether this attention to societal risk was purely instrumental in terms of avoiding the possibility that 'individuals will reject the new information culture and its instruments', it was the first time that an internationally influential body accepted and confirmed that there are indeed risks. In light of the influence this report has had for various national programmes in their approach to the development of an information society, and that these programmes have almost always paid attention to societal and human aspects of the information society, its relevance cannot be underestimated.

\section{INFORMATION SOCIETY}

In his article on the Information Society, Bell uses four criteria to judge when this entry has been accomplished [4]

- In almost all social processes, storing, processing and use of information are the central factors (information as new energy instead of the previous human power and electricity);

- More than half of the employed population consists of people working in the information sector (information as an important economic force);

- Information technology (computer and telecommunications) form the most important infrastructure in society;

- Most social and political decisions are changed drastically by the use of information and information technology (information as an important factor of change).

Looking at these criteria we can confirm that, at the start of the $21 \mathrm{st}$ century, we have indeed entered the information society, but at the same time we can raise the question: What is new in that? Have we experienced the revolution that many people would have us believe?

As we have seen, Forester first speaks of the microelectronics revolution and later of the information technology revolution. Barry Sherman uses the 
word 'The New Revolution' and even Castells uses this heavily laden word: "A technological revolution, centred around information technology, is reshaping, at accelerated pace, the material basis of society" [7].

But is this society indeed a radical new phenomenon or has it been more an evolution than a revolution? To answer this question we will reconsider the four criteria presented by Bell, starting with the importance of information.

\section{THE RISE OF THE INFORMATION SOCIETY: REVOLUTION OR EVOLUTION?}

As a consequence of the use of terminology, it is clear that the main feature of information society and information technology is information. Recording, processing and distributing information is as old as mankind. Proof of this can be seen in the caves in France, Spain and Africa, just as in Egyptian hieroglyphics. Distributing information in a very primitive form can be seen in the smoke signals of North American Indians and the horn blowers in some other countries. The importance (and consequences!) of information can also be read about in the Bible where the history of the first census takings is told. Counting people is an early instrument in the preparation of war making.

During the Middle Age the importance of information rose, strongly related to the development of the first important type of information technology: printing. Although there is discussion whether printing was first developed by the German Johannes Gutenberg or the Dutchman Laurens Janszoon Coster, there is nevertheless agreement on the importance of this invention.

As a consequence, the production of paper was stimulated, becoming one of the main products of the Industrial Age. In 1714 a new phase in this development was the invention of the typewriter by the Englishman Henry Mill, the forefather of the electric typewriter and the modern text processor. Information is more than text. Information is also a means to recording and distributing of sound and images. Thomas Edison's name is strongly related to the development of recording and distributing sound. Telephone, telex and telegraph are the results of his creativity, just as some time later was the gramophone. This development was later combined with the microphone, developed by Alexander Graham Bell and first demonstrated at the World Exhibition in Chicago in 1876.

Even more impressive is the development of the practice of recording and distributing images. For the first time images were automatically recorded successfully in the middle of the 18th century. This resulted in the first photographic-style images at the beginning of the 19th century, rapidly 
leading in the direction of the modern cameras and movies ('moving pictures'). All these inventions have come together in computer technology, which finally combines text, sound and images using the calculating principles of Pascal and numerous others.

Information is, as we have seen from this short overview, an important factor of the new form of information society, but to say that it is a new phenomenon is going too far. Information has always been important. Its importance has increased and it is perhaps more important than ever, but it cannot seen as the factor underlying society. This means at the same time that there have always been people working on the collection, processing and distribution of information. Their number has also increased. On the one side, as a consequence the number of more traditional jobs has been reduced. On the other side, new information jobs have been created (such as programmers and system analysts). All these are signs that society has changed, but it is not the first time that a new technological invention has had societal consequences. The same has been seen with telex, telephone and television. The most important difference is that we have, for the first time, a convergence of all the technical components with the result that the consequences have been more rapid and radical. However, they have not been revolutionary in the sense that the consequences are unexpected and unpredictable. One of the proofs of this is that even now, after twenty-five years, nobody can tell exactly when the information society has made its entrance, in the same way that is impossible to say when the industrial revolution came into force.

We therefore prefer to speak of gradual evolution instead of revolution. This means that we are almost never totally surprised by the consequences of the development, but in most cases can more or less predict not only what the consequences are, but also to what extent and in what areas they are likely to appear. For that reason we can even make an analytical scheme, in part based on the teaching courses presented by Jensen and Friedrich, of the fields where the consequences of the information society will become visible.

\section{TOWARDS A MODEL FOR AN INVENTORY OF THE CONSEQUENCES OF THE INFORMATION SOCIETY}

Looking at the developments of the last twenty-five years, we can see a variety of technical innovations, all of which in one way or another have influenced human life. Describing all these consequences asks for a kind of classification. The first distinction was made between consequences for the labour force and those affecting everything else. Other distinctions or classifications took the particular sector where the consequences were seen 
as a starting point: healthcare, education, business, transport, art and science, defence and the mass media. Although this type of classification had the advantage that each separate sector could be described in detail, the disadvantage was the resulting overlap. A lot of developments happened in each and every sector with consequences there for labour, privacy and human relations.

Although the classifications of Jensen and Friedrich have advantages and disadvantages, a combination of classifications has been shown to be the most appropriate analytical structure: that is, there is a distinction between macro-, meso- and micro- levels.

The macro level describes society as a whole: national and international. At that level we can think of the consequences for employment, the digital divide, distinctions between the information rich and information poor, the growing vulnerability, and the problem of information overload.

At a lower level we have the meso-level or the level of the organisation, institutions, and the people who work and live in that organisation. This includes organisational changes, quality of labour, and privacy of the employee. With privacy we are on the frontier of the meso- and the microlevel.

At the micro-level the consequences for the individual are the primary focus: telework, privacy, human relations, and family life. Although this classification - as with all analytical distinctions - has some overlaps, it has proved useful for describing the general consequences of computing.

\section{CONTROLLING INFORMATION TECHNOLOGY: THE DEBATE}

The conclusion we have made in this contribution - that technological development is an evolution rather than a revolution - is more than a mere statement. It is also a conviction that consequences may be predicted and that it is possible one way or another to control the development - in particular the all too negative consequences. This argument opposes the ruling attitude of technological determinism, which asserts that developments can neither be predicted nor controlled. Such determinism reduces humankind to powerless pawns who can only accept their fate and wait to see what other people will do to help them. It is our belief that more can be done by human beings themselves than is often admitted.

Over the course of time there has always been a vehement discussion between the optimists and pessimists regarding the possibility of controlling technology. It is as Abbe Mowshowitz observed: "The central question is the nature of technology's role in our society. Is it purely instrumental, as most observers believe; or has it become an autonomous, formative element 
in human affairs?" [18] The pessimists believe that technology is a completely autonomous power in itself that cannot be controlled. In other words, the consequences of technology, both positive as well as negative, have to be accepted as they are. ${ }^{2}$ The optimists, like Dorothy Nelkin, believe that in one way or another technology can be influenced and directed. This view is at the same time a vision of the future, so perfectly demonstrated by the statement of James Branch Cabell: "The optimist proclaims that we live in the best of all possible worlds, and the pessimist fears that this is true". 3 Langdon Winner, who made a study of autonomous technology, agrees that that it is not a conflict between pessimists and optimists, but a question of whether technology is out of control and follows its own course. In his view therefore technology influences all aspects of human life. It is a form of technological determinism that has as its characteristics firstly, that the technical base of a society is the fundamental condition affecting all patterns of social existence, and secondly, that changes in technology are the single most important source of change in society [25].

The discussion on autonomous technology and technological determinism was in particular fuelled by publication in 1954 of a book by the French sociologist and philosopher Jacques Ellul La Technique ou l'enjeu du siècle [9]. This book received international attention after its American translation to The Technological Society. In Ellul's view "technique" [technology] as a totality of methods is always striving at absolute efficiency, with the consequence that spontaneous actions disappear and we are left in a completely artificial world. In this world the individual's role will be less and less important in technical evolution. Technique has become a power endowed with its own peculiar force and is for that reason influencing everything: the economy, the state and the essence of what it is to be a human being. In that sense it even influences human behaviour, which is now oriented to adapting humankind to the technical world. In Ellul's view, in the technological society, there is no place left for a vulnerable human being. "The state, on the contrary, has need of whole, strong human beings, in full moral, intellectual, and physical vigour, who alone can serve it best. What the state requires is the technical means for integrating completely whole beings, and these means are on the point of becoming reality" $[9,386]$. It will come as no surprise that Ellul's vision on the future is gloomy. Through the developments of technique the state will become totalitarian and will absorb citizens' lives completely. Although Ellul was challenged in his opinions by numerous opponents, he never changed his mind and in later publications he repeated his forecasts of a totalitarian society.

In discussing Ellul's view of technology we should not underestimate the period in which the book was originally written (1954) - that is, the social and political context in which it was set. It was written at the time of 
the Cold War, when human beings seemed to be less important, and when they were intensively studied not only by sociological methods, but in particular by psychological testing. It was also the period of the lie detector. In that sense Ellul's pessimism to a greater or lesser extent was endorsed by philosophers like Helmut Schelsky, Erich Fromm, Forester, and Langdon Winner. It is the virtue of Winner, however, that he focussed attention on the problem of human beings in a technological society.

Ellul has been severely attacked for his pessimism, or as some have called it, fatalism. In particular his belief in technical determinism, the argument that technique is the prime mover controlling all developments, was fundamentally criticised. Determinism as a part of philosophy is a notion that has been in evidence since its beginning, only the name of prime mover has changed: God, Economy, Culture, Power. The difference is however that technical determinism in particular is criticised as not making a distinction between technology, technique and the use of technique. Freeman, Layton, and Winner are among Ellul's critics. As Winner states "Ellul fails to notice any difference between invention and technical implementation and apparently believes that for all intents and purposes these activities are identical" [25, 64]. In his, and others, view there is a clear distinction between what is happening in the laboratory and what happens when discoveries are put to work in the world at large.

Therefore a distinction should be made between the knowledge aspect and the application aspect. In some languages this distinction can be clarified in terminology between technology and technique ${ }^{4}$. Between both aspects there is a time lag, although due to technological developments this lag is becoming smaller and smaller ${ }^{5}$. But it is not only necessary to make a distinction between technology and technique, between knowledge and application, but also between the application and use of the technique. Numerous examples show how the use of technique is dependent on several societal aspects, money, the state of the art, and politics. Therefore it is too simple to say that technology is absolutely determined. Technique can, to a greater or lesser extent, be controlled.

\section{THREE FORMS OF CONTROL}

The question that we should therefore ask is: what can be done? To answer this question we would again go back to the past and offer up the old classification of Nelkin [19]. Nelkin presented a general model for control, which can be used for assessing control mechanisms. She uses the wellknown distinction between control at three stages: afterwards, before and during and calls them respectively reactive, anticipatory and participatory control. Reactive control is oriented towards the protection of interests of 
human beings and is a type of control exercised by institutions and government reacting to a certain development. Well-known forms of reactive control are legal and other punitive or disciplinary measures that attempt to prevent all too negative consequences. Also included in this category are the possibilities of claims and complaints, as are expert groups that are installed once the developments are started.

Participatory control deals with the involvement of citizens in the introduction and regulation of technology. In this capacity the most well known forms are protest movements and activities aimed at raising awareness. In some sense this has also been introduced in the labour movement under the heading of participatory design. Another form that is sometimes mentioned is self-regulation, under the condition that (consumer) organisations are involved in the process.

Anticipatory control consists of procedures for predicting social, political and economic consequences of new scientific and technological developments. This is particularly important when consequences are becoming visible, usually when the development has matured and changes are almost impossible. The most well known form of anticipatory control is Technology Assessment: identifying the possibilities of applied research and technologies together with the unwanted side effects. "It is a method of analysis that systematically appraises the nature, significance, status and merit of a technological process" [p 428].

Looking at these forms of control it is significant that reactive control is the one that is most used, followed by participatory control. Despite all pressures, participatory control has had little or no influence. For an appropriate form of control of information technology all three types of control are needed in combination. The practice, however, is that the emphasis is placed on reactive control, and for a small part on participatory control. For David Flaherty such practice gives every reason to be critical. "The belief that surveillance societies are not going to emerge because of efforts in data protection is naive; in fact, the existence of Data Protection Commissioners may actually stimulate the flavouring of surveillance societies by lulling the public into a false sense of security." [10, 381] The dangers exposed by Flaherty's observation of reactive control are alarming. A greater emphasis should be placed on the two other forms of control, anticipatory and participatory.

\section{CONCLUDING THE DISCUSSION ABOUT THE INFORMATION SOCIETY}

Reviewing these last twenty-five years and more, we can see three important periods. The first period (before 1976) can be seen as the period of growing 
awareness in several fields. The most dominant are labour and privacy. In numerous articles and books the consequences of computing, mostly in a negative sense, are predicted as a result of the emergence of the computer. The privacy discussion during this period is concerned with computer privacy, rather than informational privacy.

The second period (1976-1993) can be seen as the period of growing scientific awareness with, as an important starting point, the critical analysis of Weizenbaum who confronts computer power with the importance of human reason. Numerous analyses are made based on inventories of the consequences of computing. The publications of Dertouzos and Moses in collaboration, and Forester, are the most significant examples. It is also the time that university courses on the theme of computers and society were started. Together with these analyses some thought is given to what can be done. Faced with a dominant trend towards technological determinism, legal solutions are sought. As Nelkin observes, it is the time of reactive control.

Starting around 1993, a third period of political awareness begins. At this time, it is not the social implications that are of concern, but the consequences of these consequences. They are seen as a potential obstacle for the use and the development of the so-called electronic highway (which we now commonly think of as simply the Internet) and thus hindering the possibilities for economic growth. In an integrated way all types of measures are promoted to tackle the various social implications. A combination of legal, technical and self-regulatory measures is suggested.

What however is missing is an holistic approach - only in this way we will be able to get a real grip on the development of the information society. Such a holistic approach can be reached when at least three conditions are met:

- First of all we have to be convinced that technique is not autonomous but can in a way be predicted and controlled;

- The three stages of development in social consequences of information communication technologies - awareness, scientific knowledge and political willingness - must be integrated;

- In controlling technique a combination of reactive, participatory and anticipatory control is necessary.

It is in this arena particularly that TC 9 'Computers and Society' has attempted to focus its activities and to show the whole sphere, breadth, depth, and complexity of discussions in relation to the introduction of computing into the social arena. 


\section{REFERENCES}

1. Bell, Daniel, The Measurement of Knowledge and Technology, in: Eleanor Bernert Sheldon and Wilbert E. Moore [Eds.], Indicators of Social Change. New York: Russell Sage Foundation, 1968.

2. Bell, D., The Coming of Post-Industrial Society: A Venture in Social Forecasting. London: Heinemann, 1973.

3. Bell, Daniel, A Reply to Weizenbaum, in Dertouzos and Moses, [8], 1979, pp. 459-463.

4. Bell, Daniel, The Social Framework of the Information Society, in Dertouzos and Moses, 1989, pp. 163-212.

5. Berleur, J., A. Clement, T.R.H. Sizer and D. Whitehouse [Eds.], The Information Society: Evolving Landscapes. Report from Namur. New York: Springer Verlag-Captus University Publications, 1990.

6. Clarke, R. and J. Cameron [Eds.], Managing Information Technology's Organisational Impact. Amsterdam, New York, Oxford, Tokyo: North Holland, 1991.

7. Castells, Manuel, The Information Age, Economy, Society and Culture. Volume I: The Rise of the Network Society. Oxford, UK: Blackwell Publishers Ltd, 1996.

8. Dertouzos, Michael L. and Joel Moses [Eds.], The Computer Age: A TwentyYear View. Cambridge, Massachusetts, and London, England, 1979.

9. Ellul, Jacques, The Technological Society. New York: Vintage Books, 1964

10. Flaherty, David, 1988. The Emergence of Surveillance Societies in the Western World: Toward the Year 2000. In Government Information Quarterly, 5,4, 377387.

11. Forester, Tom [Ed.], The Microelectronic Revolution. Oxford: Basil Blackwell, 1980.

12. Forester, Tom [Ed.], The Information Technology Revolution. Oxford: Basil Blackwell, 1985.

13. High Level Group on the Information Society, Europe and the Global Information Society, in Cordis focus, Supplement 2, 15 July 1994.

14. Horowitz, E., J.L. Morgan, A.C. Shaw, Computers and society: A proposed course for computer scientists, in Communications of the $A C M, 1972$, volume 5, pp. 257-261.

15. Informatica en Maatschappij als thema voor de Informaticastudie, in Informatie, jaargang 24, nr. 4, 1982, pp. 213-224.

16. Jensen, Willy, Teaching Social and Political Consequences of Information technology, in R. Lewis \& D. Tagg [Eds.], Computers in Education. Amsterdam: North-Holland Publishing Company, 1981, pp. 503-507.

17. Kasvia, Annti, The Emergence of 'Information Society' as a Major Social Scientific Research Programme, in Erkki Karvonen, Informational Societies, Understanding the Third Industrial Revolution. Tampere: Tampere University Press, 2001, pp. 19-48.

18. Mowshowitz, Abbe, The Conquest of Will: Information Processing in Human Affairs. Reading, Mass.: Addison-Wesley Publishing Company, 1976. 
19. Nelkin, Dorothy, Technology and Public Policy, in Ina Spiegel-Rösing and Derek de Solla Price [Eds.], Science, Technology and Society, a Cross Disciplinary Perspective. London and Beverly Hills: Sage Publications, 1977, pp. 393-443.

20. Sherman, Berry, The New Revolution, The Impact of Computers on Society. Chicester, New York, Brisbane, Toronto, Singapore: John Wiley and Sons, 1985.

21. Taviss, Irene [Ed.], The Computer Impact. Englewood Cliffs, New Jersey: Prentice Hall, 1970.

22. Weizenbaum, Joseph, Computer Power and Human Reason, From Judgment to Calculation. San Francisco: W.H. Freeman and Company, 1976.

23. Weizenbaum, Joseph, Once More, the Computer Revolution, in Dertouzos and Moses, [8], 1979, pp. 439-459.

24. Westin, Alan F., Privacy and Freedom. London: The Bodley Head, 1967.

25. Winner, Langdon, Autonomous Technology, Technics-out-of Control as a Theme in Political Thought. Cambridge, Mass. And London: The MIT Press, 1977.

1 Although it is sometimes suggested that Bell was the person who introduced the term 'information society', Marien states that information society apparently was first used in Japan in the late 1960s by Kenichi Kohyama. See Michael Marien "Some Questions for the Information Society" in [12, pp. 648660].

2 As a consequence the distinction between the optimists and pessimists is not always true - some believe that this autonomous technology will bring a better world and others are opposing this.

3 Our translation of the following German expression "Der Optimist erklärt, das wir in der besten aller möglichen Welten leben; de Pessimist fürchtet, das das wahr ist". Cited in Heinz Brandt, Nostalgie als Schwellenangst, in Technologie und Politik, aktuell Magazin, nr, 1, Reinbeck bei Hamburg: Rowohlt, 1975, p.33-47.

4 It is curious that Winner mentions the distinction but at the same time uses technology and technics in the same sense in the title of his book.

5 In particular Alvin Toffler gives several examples of the diminishing lag. See Alvin Toffler, The Third Wave, New York, Toronto, London: Bantam Books, 1980. 